\title{
Placenta percreta: a rare presentation of obstetric emergency in second trimester
}

\author{
Niranjan Chavan*, Hera Mirza, Sneha Venkateswaran, Pradnya Changede
}

Department of Obstetrics and Gynecology, Lokmanya Tilak Municipal Medical College and General Hospital, Sion, Mumbai, Maharashtra, India

Received: 26 December 2019

Revised: 19 August 2020

Accepted: 20 August 2020

*Correspondence:

Dr. Niranjan Chavan,

E-mail: nnchavan22@gmail.com

Copyright: () the author(s), publisher and licensee Medip Academy. This is an open-access article distributed under the terms of the Creative Commons Attribution Non-Commercial License, which permits unrestricted non-commercial use, distribution, and reproduction in any medium, provided the original work is properly cited.

\begin{abstract}
Incidence of adherent placenta is on the rise nowadays due to various reasons. Placenta percreta is seen in 5-7\% of cases with adherent placenta, patients with morbidly adherent placenta are at increased risk for major obstetric hemorrhage, usually in the third trimester. Here we present an unusual case of placenta percreta presenting with obstetric emergency after trauma to abdomen in the second trimester. Emergency exploratory laparotomy was done for abruptio placentae with scar dehiscence at 20 weeks period of gestation. Consent for obstetric hysterectomy, if needed, was also taken. Intraoperatively, the placenta was found to be adherent to posterior wall of bladder. Emergency obstetric hysterectomy with bilateral internal iliac ligation with cystoscopy with detrusorrhaphy was done. Patient had an uneventful recovery. Multidisciplinary management with obstetricians, urologists and intensivist is presented here.
\end{abstract}

Keywords: Cystoscopy, Detrusorrhaphy, Obstetric emergency, Obstetric hysterectomy, Placenta percreta

\section{INTRODUCTION}

Placenta percreta is an abnormality of placentation where there is penetration of trophoblast through the myometrium or through the peritoneum and this may involve adjacent structures such as bladder and rectum. Placenta percreta accounts to $5-7 \%$ of adherent placenta. ${ }^{1}$ It is potentially life threatening because it can lead to catastrophic blood loss and death. Major obstetric haemorrhage is the leading cause of maternal morbidity and mortality. ${ }^{2}$

Antenatal diagnosis is required to plan delivery and minimize complications. Ultrasound or Magnetic Resonance Imaging (MRI) is useful in establishing antenatal diagnosis. We present an unusual case of placenta percreta with bladder involvement presenting with obstetric emergency in the second trimester requiring multidisciplinary team approach.

\section{CASE REPORT}

A 28 years, unregistered patient with fourth gravida, previous 2 LSCS with 20 weeks period of gestation, came to our hospital with pain in abdomen and history of fall 1 day back. She was vitally stable. There was no history of bleeding per vaginum. There was no history of major medical and surgical illness. Her obstetrical history was marked by one term intrauterine fetal death 8 years ago, which was a vaginal delivery followed by two cesarean sections (CS) 6 years and 1 year ago respectively. Both her previous CS was uneventful in antepartum and postpartum period. At presentation in the index pregnancy, on examination, there was pallor and her pulse rate were 98 beats/min. Blood pressure was 120/70 $\mathrm{mmHg}$. Cardiovascular, respiratory and nervous system were normal. Her abdomen was tense with uterus of 20 weeks size; there was guarding and severe tenderness in 
the suprapubic region. There was scar tenderness over the pfannenstiel scar. She was not bleeding per vaginally.

Obstetric ultrasound revealed a single live intrauterine gestation of 20 weeks. There was a retroplacental hematoma of approximately $200 \mathrm{ml}$. Scar thickness could not be assessed due to low lying placenta. Diagnosis was made of abruptio placentae with scar dehiscence and taken for emergency exploratory laparotomy after initial stabilization and valid informed consent.

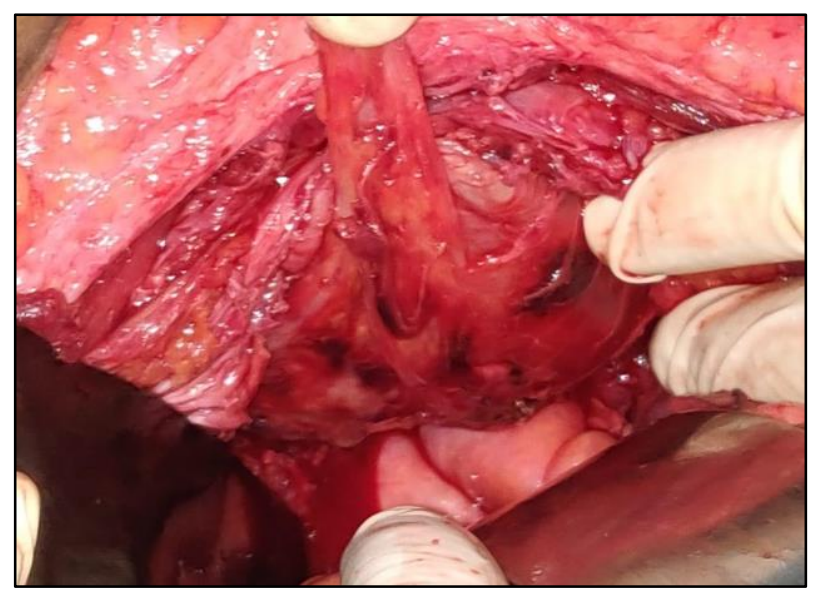

Figure 1: Placental tissue adherent to posterior wall of bladder.

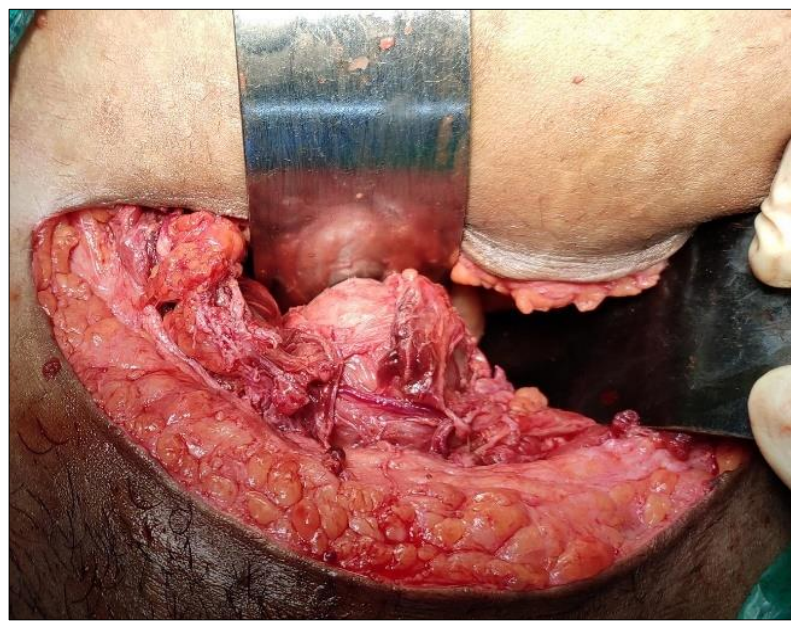

Figure 2: Placental tissue adherent to the dome of bladder.

Intraoperative finding was uterus of 20 weeks size with no hemoperitoneum, uterine scar dehiscent, amniotic membrane intact with fetus and placenta in utero. Lower segment of uterus was thinned out and could not be differentiated distinctly (Figure 3). Placenta was low lying, encroaching and densely adherent to posterior wall of bladder (Figure 1). We diagnosed placenta percreta intraoperatively. Foetus weighed $270 \mathrm{gm}$ and a retroplacental clot of $700 \mathrm{ml}$. The placenta could only be delivered partially. Lower segment of uterus was very thinned out and could not be reconstructed. Decision for emergency obstetric hysterectomy was taken and performed followed by bilateral internal iliac ligation. With the help of urologists, cystoscopy was performed as the placenta was adherent to the posterior wall of the bladder. There was a $5 \times 5 \mathrm{~cm}$ erythematous lesion involving dome and posterior wall of bladder (Figure 4). Both ureteric openings were normal. As there was no active bleeding from the placental tissue, decision was taken to leave the remnant placenta in situ was taken (Figure 2). Detrusorrhaphy was done at dome of bladder and hemostasis achieved. Post operatively patient required multiple blood and blood product transfusions. Serial ultrasound and beta hCG levels were monitored to look for bladder placental tissue autolysis. Her postoperative period was otherwise uneventful.

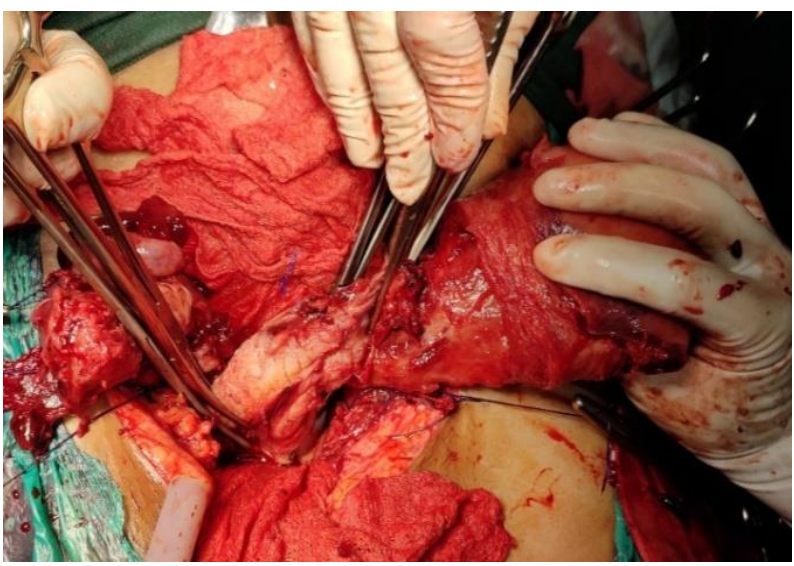

Figure 3: Thinned out lower segment.

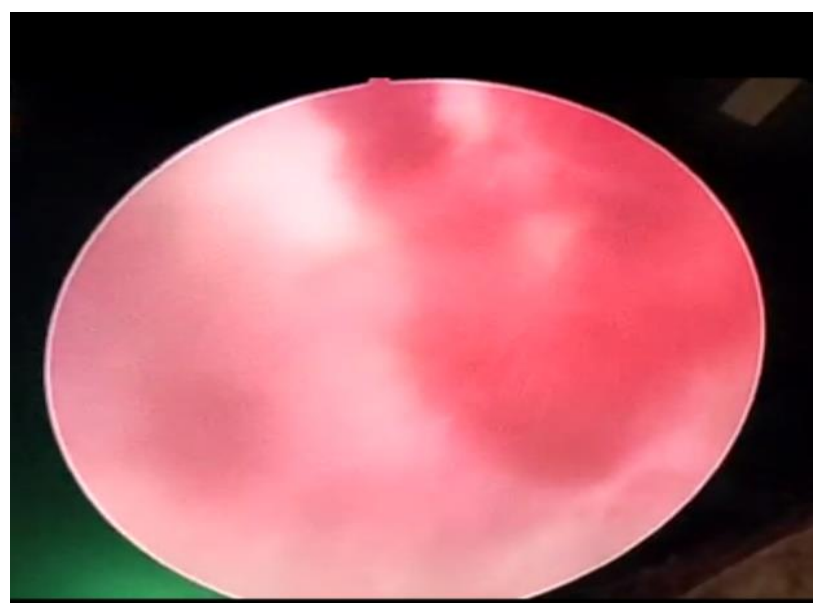

Figure 4: Erythematous lesion of $5 \times 5 \mathrm{~cm}$ is seen on bladder mucosa during cystoscopy.

\section{DISCUSSION}

Placenta percreta, the rarest and most severe form of adherent placenta. Adherent placenta occurs in approximately 1 in 2500 pregnancies. Of these, approximately $75 \%$ to $78 \%$ are placenta accreta vera, about $15 \%$ to $18 \%$ are placenta increta, and the remaining $5 \%$ to $7 \%$ are placenta percreta. ${ }^{1}$ 
Normally, a layer of decidua separates the placental villi and the myometrium (the inner layer of the uterus) at the site of placental implantation. Adherent placenta occurs when the decidua basalis is partially or totally absenting in conjunction with an imperfect development of fibrinoid (Nitabuch's) layer. Placenta accreta vera, the most superficial type, occurs when chorionic villi adhere to the superficial myometrium. Placenta increta occurs as a result of invasion of uterine musculature by placental villi. Placenta percreta, the third subtype of adherent placenta, is defined as the penetration of trophoblast through the myometrium or through the peritoneum and this may involve adjacent structures such as bladder and rectum. Major risk factor of adherent placenta includes placenta praevia, prior uterine scarring, advanced maternal age, multiparity, uterine malformation, septic endometriosis. ${ }^{3}$

Although the overall incidence of placenta percreta is extremely low, the appearance of this rare disorder seems to be increasing in the last 3 decades due to the performance of more caesarean deliveries. ${ }^{4}$ Clark et al have shown that risk of placenta previa increases proportionately with the number of prior caesarean deliveries. $(0.26 \%$ in unscarred uterus, and up to $10 \%$ in women with history of at least four CS). They have also shown that the association of placenta praevia and prior uterine scarring markedly increases the chances of adherent placenta (5\% risk in unscarred uterus, to $67 \%$ in previous four CS). ${ }^{5}$ Our patient had undergone two prior $\mathrm{CS}$ and had low lying placenta.

Antenatal diagnosis of adherent placenta aids in easy approach and management. It allows one to anticipate and recognise complications earlier that might otherwise not be expected. Complications of adherent placenta include vaginal bleeding, uterine wall rupture, invasion of adjacent organs, disseminated intravascular coagulation, complications from receiving multiple blood products. In our case, patient had suprapubic abdominal pain, there was no vaginal bleeding and placenta was found to be adherent to posterior wall of bladder. Most cases of placenta percreta that involve the bladder are recognized only at the time of delivery. Gross hematuria, surprisingly, is rare even when the bladder is invaded and occurs in only about $25 \%$ of such cases. ${ }^{6}$ Unlike the painless third trimester prepartum haemorrhage common with placenta previa, vaginal bleeding of placenta percreta is more likely to be painful due to invasion of the hemorrhaging placental tissue into the uterine wall. Some patients with placenta percreta have even described a history of dull, continuous lower abdominal pain during their pregnancy. ${ }^{4}$ When a multiparous woman with a history of a previous caesarean delivery is found to have a placenta previa, the possibility of placenta percreta should be suspected.

Evaluation to identify whether placenta percreta may be present includes ultrasound, magnetic resonance imaging (MRI), and cystoscopy. Grayscale ultrasonography, when performed in the first trimester, will reveal a low-lying uterine sac with a thin myometrium. Sonographic findings during the second and third trimester include placental lacunae (vascular lakes of various shapes and sizes seen within placental parenchyma) an irregular border between the bladder and myometrium, a thin myometrium, and loss of clear space (loss of the decidual layer of the placenta). ${ }^{7,8}$ Doppler ultrasonography will often reveal turbulent blood flow extending from the placenta to surrounding tissues. MRI may reveal nonvisualization of the inner layer of the placentamyometrium interface on half-Fourier single-shot turbo spin-echo images. ${ }^{9}$ Cystoscopy may often show posterior bladder wall abnormalities. Biopsy and/or fulguration of these abnormalities should be avoided, as this may precipitate massive hemorrhage. ${ }^{6}$

In the setting of a preoperative diagnosis of placenta accreta, manual removal of the placenta should be avoided. No intervention should be entertained until delivery of the baby has occurred. Once delivery has occurred, the presence of unstoppable uterine bleeding from the retained part of the placenta may force the obstetrician to perform a hysterectomy. Intraoperative internal iliac artery embolization after preoperative cannulation or prophylactic bilateral ligation may be performed to prevent excessive blood loss at the time of hysterectomy. ${ }^{1}$ If uterine bleeding from the retained placenta percreta is controlled after delivery, consideration for the use of methotrexate rather than any further surgical intervention should be considered. Similar to its use in management of ectopic pregnancy, oral methotrexate will destroy all viable products of conception by its inhibition of dihydrofolate reductase. Conservative management with methotrexate should be performed with caution, however, and complications such as delayed bleeding should be expected. ${ }^{10}$ In the presence of bladder wall invasion and in the setting of uncontrolled uterine bleeding following delivery, every attempt should be made to preserve the bladder.

A firm preoperative diagnosis allows adequate preparation and organization of multidisciplinary help for what may be a difficult surgical procedure requiring massive blood transfusion. Use of newer intervention techniques and alternate surgical approaches may decrease morbidity and blood loss.

\section{CONCLUSION}

Early antenatal diagnosis permits effective and safe conservative approaches. We should be prepared to deal with the crisis when faced with undetected adherent placenta during delivery or caesarean section.

\author{
Funding: No funding sources \\ Conflict of interest: None declared \\ Ethical approval: Not required
}




\section{REFERENCES}

1. Hudon L, Belfort A, Broome R. Diagnosis and management of placenta percreta: a review. Obstet Gynecol Surv. 1998;53:509-17.

2. Mercier J, Van de Velde M. Major obstetric hemorrhage. Anesthesiol Clin. 2008;26:53-66.

3. Poggi H, Kapernick S. Postpartum hemorrhage and abnormal puerperium. In: DeCherney $\mathrm{AH}$, Nathan L, eds. Current Diagnosis and Treatment Obstetrics and Gynecology. 10th ed. New York: McGraw-Hill Medical; 2007:531.

4. Abbas F, Talati J, Wasti S, Akram S, Ghaffar S, Qureshi R. Placenta percreta with bladder invasion as a cause of life-threatening hemorrhage. J Urol. 2000;164:1270-74.

5. Clark L, Kooninas P, Phelan P. Placenta previa/accrete and non-cesarean section. Obstet Gynecol. 1975;66:89-92.

6. Takai N, Eto M, Sato F, Mimata H, Miyakawa I. Placenta percreta invading the urinary bladder. Arch Gynecol Obstet. 2005;271:274-5.
7. Yang JI, Lim YK, Kim HS, Chang KH, Lee JP, Ryu HS. Sonographic findings of placental lacunae and the prediction of adherent placenta in women with placenta previa totalis and prior cesarean section. Ultrasound Obstet Gynecol. 2006;28:178-82.

8. Finberg HJ, Williams JW. Placenta accreta: prospective sonographic diagnosis in patients with placenta previa and prior cesarean section. J. Ultrasound Med. 1992;11:343.

9. Comstock H. Antenatal diagnosis of placenta accreta: a review. Ultrasound Obstet Gynecol. 2005;26:89-96.

10. Hays M, Worley C, Roberts R. Conservative management of placenta percreta: experiences in two cases. Obstet Gynecol. 2008;112:425-26.

Cite this article as: Chavan $\mathrm{N}$,Mirza $\mathrm{H}$

Venkateswaran S, Changede P. Placenta percreta: a rare presentation of obstetric emergency in second trimester. Int J Reprod Contracept Obstet Gynecol 2020;9:4295-8. 